\title{
Capítulo
}

3

\section{Metodologia de Pesquisa - Estudo de Caso Interpretativo em Sistemas de Informação}

\author{
Nadja Piedade de Antonio, Marcelo Fornazin, Renata Mendes de Araujo e \\ Rodrigo Pereira dos Santos
}

\begin{abstract}
The objective of this chapter is to instruct researchers, students and professionals on how to perform research using Interpretative Case Study Methodology to analyze Information Systems (IS) in their practical contexts of production and use. The chapter will address the differences between interpretive and positivist research, as well as positioning Interpretative Case Studies (ICS) in relation to other research methods. In addition, we will discuss the quality criteria to perform an ICS in IS. We will also present techniques for conducting ICS, and how they can be used to produce knowledge about IS in practical contexts.
\end{abstract}

\section{Resumo}

$O$ objetivo deste capitulo é capacitar pesquisadores, alunos e profissionais a realizarem pesquisas utilizando a Metodologia de Estudo de Caso Interpretativo para a análise de Sistemas de Informação (SI) em seus contextos de produção e uso. Este minicurso irá abordar as diferenças entre os paradigmas de pesquisas positivistas e interpretativos, bem como posicionar o Estudo de Caso Interpretativo (ECI) em relação a outras metodologias de pesquisa. Além disso, serão discutidos os critérios de qualidade para se realizar um ECI em SI. Também serão apresentadas técnicas para condução de ECI e como elas podem ser empregadas para produzir conhecimento sobre SI em contextos práticos. 


\subsection{Introdução}

Cada vez mais percebe-se a complexidade ${ }^{1}$ em se desenvolver e gerir Sistemas de Informação (SI), com as nuances e particularidades inerentes ao contexto, bem como aos autores envolvidos na produção e uso desses sistemas. Isto converge com o tema central do XV Simpósio Brasileiro de Sistemas de Informação (SBSI 2019), e nos ajuda a discutir, problematizar e pensar os SI modernos.

Experiências anteriores demonstram a condição e a importância de que os estudos de SI devem se dar de forma interdisciplinar, envolvendo conhecimentos sobre tecnologias, pessoas e organizações [Hirschheim e Klein, 2011; Recker, 2013; Laudon e Laudon, 2014; Boscarioli et al., 2017]. Sendo assim, como profissionais e pesquisadores de SI, trazemos aqui algumas provocações iniciais, tanto sobre pesquisa como práticas: Será um SI apenas um artefato tecnológico? Como pensamos o contexto de uso dos SI? Como consideramos os conhecimentos organizacionais e sociais ao pensarmos os SI? Somos executores de demandas de desenvolvimento ou procuramos entender a complexidade existente nos SI? ${ }^{2}$

Porém, no âmbito nacional, nos encontramos ainda distantes da interdisciplinaridade nos estudos de SI. Araujo et al. (2017) observaram que, em meio aos artigos publicados na Revista Brasileira de Sistemas de Informação (iSys) ${ }^{3}$, há um desafio em reconhecer o potencial científico decorrente de uma abertura a outras formas de pensamento que compreendam a complexidade do mundo real, essencial para o estudo dos SI. Assim, entendemos ser fundamental a elaboração de pesquisas a partir de paradigmas que considerem o contexto de uso dos SI, tais como o interpretativo [Walsham, 1993], o sociomaterial [Orlikowski e Scott, 2008] e o projetivo (Design Science Research) [Pimentel et al., 2017].

Os paradigmas acima citados permitem lançar mão de outras metodologias de pesquisa, como estudo de caso, etnografia e pesquisa-ação. Tais metodologias científicas permitem compreender o SI em seu contexto de produção e uso, sem transportá-lo para o espaço controlado dos laboratórios e simuladores, revelando assim a complexidade interdisciplinar do SI.

Apesar das pesquisas interpretativas serem pouco difundidas e debatidas na comunidade científica nacional, no âmbito internacional já existem pesquisadores que há muito defendem a importância desta abordagem. De acordo com Walsham (1995), o paradigma interpretativo pode ajudar os pesquisadores de SI a entenderem o pensamento humano e a ação em contextos sociais e organizacionais. Além disso, tem o

\footnotetext{
${ }^{1}$ Cabe notar que, neste capítulo, estamos utilizando o vocábulo complexidade sem referência ao pensamento complexo, como, por exemplo, proposto por Edgar Morin. Nossa menção a este termo visa chamar a atenção para elementos sociais, culturais, econômicos e políticos, que são poucos considerados pelas pesquisas em SI. Para superar isso, faz-se necessário encarar um cenário mais complexo, heterogêneo e incerto que o observado no enquadramento das pesquisas formais e quantitativas.

${ }^{2}$ A escrita na primeira pessoa do plural é uma escolha de comunicação preconizada nas pesquisas interpretativas e em outras áreas das ciências sociais. Aceitando que o pesquisador não é neutro, fazemos essa escolha como pesquisadores para nos aproximarmos dos sujeitos das pesquisas e dos leitores. Contudo, não abdicamos do rigor da pesquisa científica e, mesmo escrevendo na primeira pessoa, buscamos o distanciamento crítico necessário para refletir sobre nossas pesquisas. Para mais informações sobre escrita científica na primeira pessoa ver Pozzebon (2004) e Walsham (2006).

${ }^{3}$ iSys é uma das principais revistas na área de SI no Brasil, gerenciada pela Comissão Especial em SI da Sociedade Brasileira de Computação. Detalhes em http://www.seer.unirio.br/index.php/isys.
} 
potencial de produzir descobertas profundas sobre os fenômenos dos SI nas esferas do gerenciamento e desenvolvimento destes. Ou seja, é importante problematizar o contexto social dos SI pois, caso contrário, conforme nos alertam Orlikowski e Iacono (2001), permaneceremos observadores passivos das transformações técnico-sociais que ocorrem ao nosso redor.

Para além da pesquisa científica, principalmente em processos de inovação tecnológica, são cada vez mais relevante abordagens alternativas para se compreender a complexidade dos SI em seus contextos de uso. Araujo e Chueri (2017) argumentam que, quando consideramos o processo de inovação, é necessário observar contextos organizacionais, sociais ou de mercado para identificação de problemas e oportunidades, ao mesmo tempo que é exigida a análise do impacto do produto inovador em uso.

Em áreas como a Sociologia e Administração, muitas vezes se utilizam os estudos de casos para compreender o contexto de interesse da pesquisa, deixando a problematização da tecnologia para um segundo plano, tratando os artefatos tecnológicos como caixas pretas ou ferramentas prontas. Já na Computação, os estudos de caso são utilizados nas áreas: Interação Humano-Computador (IHC), Sistemas Colaborativos e Engenharia de Software Experimental. Está última vem advogando sobre a importância de métodos qualitativos [Runeson et al., 2012; Wohlin et al., 2012]. Contudo, os estudos de caso são empregados majoritariamente para se obter acesso ao ambiente de uso de um software em maior profundidade do que experimentos ou levantamentos poderiam prover, sem necessariamente problematizar o contexto organizacional em que o SI está imerso.

Entretanto, estudos de caso na área de SI se diferenciam dessas duas formas, pois se dedicam a estudar a relação entre o SI e seu contexto de uso, problematizando ambos. Nesse ponto, nos baseamos na definição de Orlikowski e Iacono (2001), na qual o SI é visto em conjunto com o seu contexto, por meio de interações dinâmicas entre pessoas e tecnologias, em que os SI moldam práticas organizacionais, ao mesmo tempo que são moldados por elas, por exemplo: comunidades de software livre, comércio eletrônico, redes sociais e novas formas de trabalho e de participação política. Além disso, questões emergiram, tais como desafios de propriedade intelectual e privacidade. É justamente nesse ponto da relação entre os SI e seus contextos de uso que os pesquisadores de SI podem explorar ao limite suas habilidades de problematizar ambos (tecnologia e contexto).

Neste capítulo, buscamos estudar a questão sobre como pesquisar SI em seus contextos a partir da metodologia de pesquisa Estudo de Caso Interpretativo (ECI). Os ECI, partindo de uma visão social e subjetiva dos SI, consideram o contexto e a complexidade nos quais ele está inserido. Ao longo deste capítulo apresentaremos a metodologia citada em seus detalhes conceituais e práticos como forma de sistematizar as técnicas para estudar casos de SI. Assim, objetivamos fomentar o uso de ECI em pesquisas e em atividades profissionais na área de SI.

O capítulo está organizado da seguinte forma: além desta Introdução, na Seção 3.2 discutiremos dois principais paradigmas de pesquisa na área de SI, quais sejam, o positivista e o interpretativo. Na Seção 3.3 apresentaremos o método de ECI, evidenciando suas diferenças em relação a outras formas de estudo de caso. Além disso, mostraremos exemplos de ECI de Alvarez (2008), Avgerou et al. (2009) e Chua e 
Myers (2017) como forma de ilustrar essa abordagem de pesquisa. Na Seção 3.4, discutiremos princípios de qualidade que os ECI devem assegurar e, na Seção 3.5, traremos sugestões para condução, análise e relatórios de ECI. Na Seção 3.6, encerraremos o capítulo com nossas considerações finais.

\subsection{Paradigmas de Pesquisa em SI}

A comunidade de pesquisa em SI que emerge da área de pesquisa da Computação, estabelece, de forma natural, suas práticas de pesquisa a partir do pensamento majoritário praticado nas ciências exatas. Essa forma de pesquisa é calcada em medições objetivas realizadas por meio de escalas numéricas e técnicas estatísticas, bem como no estabelecimento de relações causais descritas por meio de modelos e equações. Ademais, a pesquisa geralmente é realizada em atividades de laboratório, tais como experimentos e simulações, conforme explicado por Wazlawick (2009).

Contudo, a área de SI é interdisciplinar; pois além da Computação, também envolve conhecimentos sobre pessoas e organizações. Assim, pesquisas inspiradas em teorias e métodos das ciências sociais também passaram a endereçar temas de SI. Exemplos de teorias sociais que explicam a produção, uso e implicações SI são a Teoria Institucional [Avgerou, 2000], a Teoria da Estruturação [Orlikowski e Robey, 1991] e a Teoria Ator-Rede [Latour, 2012; Sahay e Walsham, 2006]. Na Subseção 3.3.1, apresentamos de modo mais detalhado alguns exemplos de pesquisas desta mesma natureza.

Parte das pesquisas em SI, portanto, não se baseia na objetividade das ciências exatas, mas em abordagens subjetivas que buscam compreender como os artefatos tecnológicos são concebidos na consciência das pessoas e grupos sociais. Neste capítulo, para fins didáticos, apresentaremos dois paradigmas de pesquisa ${ }^{4}$, quais sejam, o paradigma positivista e o paradigma interpretativo. Não é adequado estabelecer uma relação direta de equivalência entre os dois paradigmas, mas podemos identificar suas diferenças. Ou seja, não há um paradigma melhor que outro, mas questões e métodos mais adequados a pesquisas conduzidas sob um ou outro paradigma. Assim, nos próximos parágrafos, introduziremos brevemente os dois paradigmas, suas raízes filosóficas e exemplos de pesquisas neles inspiradas. Além disso, faremos uma discussão entre eles, levando em conta a ontologia e a epistemologia de cada paradigma. Ao final da seção apresentamos alguns exemplos de métodos de pesquisa e explicamos como eles se filiam a um ou outro paradigma 5 .

O paradigma positivista, pressupõe que o conhecimento científico reside na objetividade, baseado em medições e modelos matemáticos, orientado pelos princípios

\footnotetext{
${ }^{4}$ A noção de paradigma de pesquisa aqui apresentada baseia-se em Kuhn (1975), para o qual paradigmas são as "realizações científicas universalmente reconhecidas que, durante algum tempo, fornecem problemas e soluções modelares para uma comunidade de praticantes de uma ciência" (p.13).

${ }^{5} \mathrm{Na}$ área de SI, desde a década de 1980 se discutem os paradigmas de pesquisa [Markus e Robey, 1988; Hirschheim e Klein, 1989]. O paradigma positivista, nos anos 1980 , guiou quase de $97 \%$ das pesquisas em SI [Orlikowski e Baroudi, 1991] e, nos anos 1990 e 2000, continuou majoritário com 85\% dos trabalhos publicados nos principais periódicos internacionais [Palvia et al., 2017]. O paradigma interpretativo, ainda que minoritário, se estabeleceu como uma forma consistente de se fazer pesquisa em SI e hoje inspira em torno de $10 \%$ das pesquisas no cenário internacional [Palvia et al., 2017]. Há outros paradigmas de pesquisa na área SI, como, por exemplo, o crítico, o projetivo e o sociomaterial. Contudo, optamos por focar nossa discussão entre o paradigma positivista e o paradigma interpretativo.
} 
da racionalidade formal ou instrumental que reduz o universo dos observáveis ao quantificável. Esse paradigma preconiza uma apreensão da realidade na forma de modelos operacionalizados por meio do racionalismo cartesiano, que busca dividir e classificar um problema para depois determinar regularidades, padrões e relações causais entre construtos teóricos. Por exemplo, criam-se leis da natureza da economia, visando explicar os fenômenos e prever seus comportamentos [Araujo et al., 2017]. Questões do tipo "o quanto um algoritmo A é mais eficiente que um algoritmo B?" são melhor respondidas por meio de procedimentos formais e experimentais os quais se vinculam ao paradigma positivista.

Um exemplo de estudo baseado no paradigma positivista é o Modelo de Aceitação de Tecnologia, em inglês Technology Acceptance Model - TAM [Davis, 1989]. O artigo seminal do TAM colocou como objetivo de pesquisa: "perseguir melhores medidas para predizer e explicar o uso de sistemas de informação" [Davis, 1989, tradução nossa]. Nota-se aqui que o estudo almejou medir o uso de SI, i.e., um procedimento objetivo. Para tanto, Davis elaborou e validou uma escala de medição baseada em fatores objetivos, quais sejam: a facilidade de uso e a utilidade percebidas do SI. O modelo TAM foi posteriormente replicado em milhares de estudos que buscaram medir o uso de sistemas.

O paradigma positivista se tornou hegemônico na ciência e na sociedade. Muitas descobertas científicas importantes, tais como os achados que se tornaram vacinas, computadores, aviões etc., foram feitas a partir de pesquisas inspiradas pelo paradigma positivista. Contudo, nem sempre é possível reproduzir em laboratório a realidade de organizações, grupos sociais e situações de produção e uso de SI. Assim, para lidar com fenômenos instáveis e não facilmente delimitados, emergiram pensamentos alternativos, como a pesquisa interpretativa.

$\mathrm{O}$ paradigma interpretativo ${ }^{6}$ tem como premissa fundamental que "nosso conhecimento da realidade, incluindo o domínio da ação humana, é uma construção social de atores humanos" [Walsham, 2006]. Conforme Orlikowski e Baroudi (1991) explicam, a ontologia do paradigma interpretativo em SI "assume que o mundo social (i.e., relações sociais, organizações, divisão de trabalho) não são 'dadas' [pela natureza]. Ao contrário, o mundo social é produzido e reforçado pelos humanos por meio de suas ações e interações" (grifos nossos).

O paradigma interpretativo é praticado por pesquisadores e intelectuais desde o século XIX, como, por exemplo, a fenomenologia de Edmund Husserl e sociologia Weberiana [Burrell e Morgan, 1979]. Na segunda metade do século XX, cada vez mais disciplinas acadêmicas que estudam questões sociais - entre elas, a Sociologia, a Psicologia e a Administração - passaram a se debruçar sobre o paradigma interpretativo para teorizar sobre seus fenômenos de estudo. Esse também foi o caso da área de SI que, a partir dos anos 1980, passou e debater pesquisas inspiradas pelo paradigma interpretativo.

Desse modo, "teorias em relação à realidade são meios de produzir senso do mundo, e entendimentos compartilhados são uma forma intersubjetiva ao invés de

\footnotetext{
${ }^{6}$ Para conhecer mais a fundo os pressupostos ontológicos e epistemológicos do paradigma interpretativo, consultar: Markus e Robey (1988), Hirschheim e Klein (1989), Orlikowski e Baroudi (1991), Walsham (1993).
} 
objetividade" [Walsham, 2006]. No paradigma interpretativo, portanto, os SI são compreendidos de maneira subjetiva a partir das relações entre as pessoas e, assim, não são um objeto estritamente técnico, mas um fenômeno social a ser interpretado.

Nos estudos realizados sob o paradigma interpretativo, não se busca uma análise objetiva do fato científico, mas uma interpretação narrativa. Desse modo, não pressupõe um ambiente estável e bem delimitado para obtenção de medidas objetivas, mas é permitido ao pesquisador compreender um fenômeno em seu contexto social. A visão interpretativa concebe que o conhecimento emerge em meio às interações sociais. Questões do tipo "como um sistema evolui e envolve atores ao longo do tempo", diferentes das formuladas sob o paradigma positivista, podem ser melhor estudadas por meio de métodos históricos e observacionais que apresentam uma narrativa e se aproximam do paradigma interpretativo.

Assim, as pesquisas conduzidas sob o paradigma interpretativo são estudos de campo que investigam as pessoas em seus contextos sociais. Contudo, seguindo o pressuposto de que a realidade é socialmente construída, evitam impor a um fenômeno categorias previamente definidas na literatura científica [Orlikowski e Baroudi, 1991]. Isso quer dizer que a pesquisa interpretativa evita enquadrar o SI a um modelo teórico prévio e propõe um diálogo entre teoria e campo, por meio do qual emergem as reflexões e teorizações [Klein e Myers, 1999].

Um exemplo de pesquisa inspirada no paradigma interpretativo é o estudo de Markus (1983) sobre a resistência a Sistemas de Informação. A autora, após revisar a literatura, discute três correntes de análise da resistência aos SI. Uma primeira corrente de pensamento entende que os SI sofrem resistência devido às suas características técnicas, ou seja, problemas nas especificações técnicas de um SI levam a questionamentos e comportamentos de resistência. Outra corrente identifica que a resistência está atrelada a determinados tipos de usuários. Isto é, alguns usuários teriam maior tendência a demonstrar resistência no uso de SI. Essas duas correntes, segundo Markus (1983), se baseiam em visões objetivas dos SI ou de seus usuários, de modo que seria possível identificar características objetivas e mensuráveis e, eventualmente, formular recomendações para se corrigir os SI ou mudar os usuários.

Contudo, Markus (1983) interroga que isto dificilmente acontece na prática, pois os mesmos SI são usados de forma diferente em contextos diferentes. Markus (1983) observou a emergência da resistência em situações práticas, acompanhando o dia-a-dia de organizações e conversando com os usuários para compreender as diferentes visões (interpretações) que eles fazem do SI. Ela então propôs uma terceira corrente de análise da resistência, chamada interacional. $\mathrm{Na}$ abordagem interacional, a resistência acontece durante a interação do SI com o contexto uso, mais precisamente a resistência pode emergir de mudanças na forma de se realizar o trabalho ou na redistribuição do poder em uma organização.

Outro exemplo é o trabalho de Chua e Myers (2017) que, ao investigarem o controle em projetos de SI, "proveram um entendimento mais sutil das forças sociais que afetam o controle nos sistemas de informação". Esse argumento buscou responder a questão até então não resolvida: "como forças sociais e ordens negociadas afetam a forma que clientes asseguram que fornecedores desempenham os níveis de satisfação definidos". Podemos notar que a pergunta versa sobre "como" algo acontece e resposta apresenta sutilezas e nuances de um processo que não são captadas por medidas 
objetivas. Para tanto, os autores conduziram um estudo de caso sob o paradigma interpretativo e, após observações, entrevistas e análise de documentos, apresentaram uma série de influências sociais sobre a relação entre clientes e fornecedores de serviços de tecnologia. Contudo, alertaram que essas influências eram sutis e não poderiam ser observadas de maneira isolada do contexto de uso do SI.

Cada paradigma possui metodologias de pesquisa próprias. A Tabela 3.1 apresenta uma associação entre metodologias, paradigmas e características de uma pesquisa.

Tabela 3.1 - Metodologias de pesquisa e paradigmas (adaptado de Yin (2001)).

\begin{tabular}{|c|c|c|c|c|}
\hline $\begin{array}{l}\text { metodologia } \\
\text { de pesquisa }\end{array}$ & $\begin{array}{l}\text { paradigma de } \\
\text { pesquisa } \\
\text { relacionado }\end{array}$ & $\begin{array}{l}\text { forma de } \\
\text { questão de } \\
\text { pesquisa }\end{array}$ & $\begin{array}{l}\text { exige controle } \\
\text { sobre eventos? }\end{array}$ & $\begin{array}{c}\text { focaliza } \\
\text { acontecimentos } \\
\text { contemporâneos? }\end{array}$ \\
\hline experimento & positivista & quanto, porque & $\operatorname{sim}$ & $\operatorname{sim}$ \\
\hline $\begin{array}{l}\text { pesquisa de } \\
\text { opinião }\end{array}$ & positivista & $\begin{array}{l}\text { quem, o que, } \\
\text { onde, quanto }\end{array}$ & $\operatorname{sim}$ & $\operatorname{sim}$ \\
\hline pesquisa-ação & $\begin{array}{l}\text { positivista, } \\
\text { interpretativo }\end{array}$ & como, porque & $\operatorname{sim}$ & $\operatorname{sim}$ \\
\hline $\begin{array}{l}\text { design science } \\
\text { research }\end{array}$ & projetivo & como, porque & $\operatorname{sim}$ & $\operatorname{sim}$ \\
\hline estudo de caso & $\begin{array}{l}\text { positivista, } \\
\text { interpretativo }\end{array}$ & como, porque & não & sim/não \\
\hline etnografia & interpretativo & como, porque & não & sim/não \\
\hline $\begin{array}{l}\text { pesquisa } \\
\text { histórica }\end{array}$ & interpretativo & $\begin{array}{l}\text { quem, o que, } \\
\text { onde, como }\end{array}$ & não & não \\
\hline
\end{tabular}

Em relação às metodologias quantitativas, o experimento e a pesquisa de opinião são dominantes nas pesquisas de SI. O experimento pressupõe a construção do artefato tecnológico no laboratório e em seguida a submissão deste a sucessivos testes, de modo a obter medidas quantitativas [Recker, 2013]. O objetivo destas medidas é demonstrar a diferenciação ou avanço tecnológico do artefato em relação aos resultados previamente demonstrados na literatura. A pesquisa de opinião se trata de obtenção dos dados ou informações de um determinado grupo de pessoas de forma sistemática, observando-se padrões nestes dados coletados [Kitchenham, 2006].

$\mathrm{Na}$ pesquisa-ação, o pesquisador realiza duas ações: uma de melhoria numa organização ou comunidade ao mesmo tempo em que se realiza outra de pesquisa científica naquele contexto real. Quase sempre é realizado um processo iterativo, envolvendo as etapas diagnosticar-agir-avaliar-refletir, para que a solução seja construída e refinada a cada ciclo da pesquisa [Araujo et al., 2017]. Já no design science research, o pesquisador além de entender o contexto do SI, busca construir um artefato (SI, processo, modelo, arquitetura, framework) com intuito de modificar a realidade na qual aquele SI está inserido [Pimentel et al., 2017]. 
O estudo de caso é realizado no contexto de uso do SI gerando conhecimento científico sobre aquele contexto específico, não sendo possível estudá-lo fora do seu contexto de uso [Yin, 2001]. A etnografia é uma metodologia para se produzir conhecimento aprofundado por meio da observação direta do pesquisador que se insere em um contexto real com o objetivo de entender os valores e as práticas de uma dada organização ou comunidade [Myers, 1999; Araujo et al., 2017]. Por fim, na pesquisa histórica, o pesquisador visa escrever uma história acerca de um tema ao longo de um período específico [Porra, Hirschheim e Parks, 2014] e faz uso de evidências e documentos para construir uma narrativa baseada em sua interpretação e visão de mundo. Na próxima seção, apresentamos o conceito de estudo de caso e de paradigmas de pesquisa.

\subsection{Estudo de Caso e Paradigmas de Pesquisa}

Algumas características do estudo de caso são similares, tanto no paradigma positivista quanto no paradigma interpretativo. Contudo, há diferenças teóricas e metodológicas que não podem ser confundidas durante a realização de estudo de caso de um ou outro tipo. Nesta seção, apresentamos o ECI e o comparamos com o seu análogo positivista 7 . Para tanto, iniciamos definindo estudo de caso e, em seguida, discutimos as diferenças entre os Estudos de Caso Positivistas (ECP) e os ECI sob quatro dimensões: premissas ontológicas e epistemológicas; a função do estudo de caso em meio a outros métodos; a relação do pesquisador com o campo e os sujeitos de pesquisa, e os critérios de rigor e qualidade do estudo de caso em cada paradigma. Ao final da seção, discutimos a diferença entre o método científico estudo de caso, casos de ensino e casos ilustrativos.

De um modo geral, os estudo de caso são adequados para pesquisas que buscam responder perguntas do tipo "COMO" e "POR QUÊ?", as quais não podem ser respondidas apenas por medidas quantitativas, mas necessitam de uma explicação contextual, por exemplo, que descreva o SI em sua trajetória cronológica e dinâmica social. Yin (2001) define estudo de caso como um método de pesquisa adequado para situações em que é difícil se estabelecer um delineamento claro entre o fenômeno estudado e seu contexto, de modo que não é possível investigar o fenômeno fora de seu ambiente prático. Por exemplo, Kling e Scacchi (1982) criaram os "web models" que examinam como o uso dos SI dependem de um determinado contexto social. Este contexto social é definido pelas relações sociais que são formadas pelos participantes neste SI, pela infraestrutura (hardware) e pelo histórico da organização na qual o SI está inserido.

A principal diferença entre os ECP frente aos ECI é que, no paradigma positivista, os estudos de caso são realizados em consonância com uma visão racionalista e objetiva do mundo [Araujo et al., 2017]. Assim, buscam produzir relatos objetivos dos SI a partir dos casos, apresentando variáveis e modelos causais, os quais possam ser posteriormente testados por métodos quantitativos. Ou seja, sob o paradigma positivista, os estudos de caso buscam estabelecer relações causais entre construtos teóricos e testar hipóteses e partir de análises detalhadas de casos empíricos. Desse

\footnotetext{
${ }^{7}$ Não é objetivo deste capítulo apresentar os estudos de caso positivistas, mas faremos referência aos seus pressupostos e técnicas como forma de explicar as diferenças para os Estudos de Caso Interpretativos. Um manual do Estudo de Caso Positivista pode ser acessado em trabalho prévio de Antonio et al. (2018). Mais informações sobre os Estudos de Caso Positivistas podem ser encontradas em Benbasat et al., (1987)/, Yin (2001) e Dubé e Paré (2003).
} 
modo, embora qualitativos, os ECP buscam se aproximar dos pressupostos das pesquisas quantitativas.

Por sua vez, um ECI, conforme explicado por Klein e Myers (1999), assume que o nosso conhecimento da realidade é obtido apenas por meio de construções sociais como linguagem, consciência e significados compartilhados. Desse modo, um ECI não define variáveis que possam ser medidas de modo objetivo, nem estabelece relações de causa e efeito, mas focaliza a complexidade da tomada de sentido humano à medida que a situação emerge e tenta entender os fenômenos através dos significados que as pessoas atribuem a eles. Nos ECI, múltiplas interpretações podem coexistir sobre o mesmo caso. As visões distintas de cada ator envolvido no estudo de caso irão variar de acordo com a vivência, experiência e momento [Klein e Myers, 1999].

Por meio dos ECI, observa-se o contexto de uso de um SI, considerando tecnologia, pessoas e organizações. Pozzebon e Freitas (1998) trazem a necessidade de investigar o relacionamento entre os SI por meio de aspectos humanos (cognitivos, psicológicos, sociais, culturais) e técnicos (ergonomia, projeto), sendo que estes devem ser levados em conta de forma integrada.

O objetivo dos ECI, portanto, não é identificar relações causais, mas descrever condições que porventura estejam relacionadas a um fenômeno que emerge das interações sociais. Tais condições estão associadas ao fenômeno, mas dada a sua complexidade, não são suficientes para atribuir uma relação direta de causa e efeito [Markus e Robey, 1988]. Para exemplificar, Chua e Myers (2017) buscaram refinar a compreensão sobre o controle em contratos de fornecimento serviços e TI, sem, no entanto, simplificar a sua análise a fatores objetivos para medição do controle. $\mathrm{O}$ paradigma interpretativo em SI, portanto, é "destinado a produzir uma compreensão do contexto do SI, e o processo pelo qual o SI influencia e é influenciado pelo contexto" [Walsham, 1993].

Os ECP são particularmente apropriados para certos tipos de problemas: aqueles em que a pesquisa e a teoria estão em seus estágios iniciais de formação e onde serão estudados problemas que são baseados na prática, onde as experiências dos atores são importantes e o contexto de ação é crítico [Benbasat et al., 1987].

Já no paradigma interpretativo, os ECI são um meio de se acumular conhecimento e reflexão sobre o mundo. Ou seja, não se busca apenas usar os estudos de caso para explorar o mundo e gerar teorias que possam ser posteriormente testadas por meio de métodos quantitativos. Conforme Walsham (1995) esclarece, os ECI podem gerar explicações que sejam válidas no futuro para outros contextos. Assim, no paradigma interpretativo, o conhecimento não é descrito por meio de modelos e equações, mas por casos que relatam aspectos do mundo socialmente construído e permitem compreender ideias, concepções, implicações e reflexões sobre os SI em seus contextos práticos.

Os estudos de caso em ambos os paradigmas requerem que o pesquisador esteja inserido no contexto do SI a fim de conseguir observar o fenômeno de investigação de forma detalhada. Contudo, no ECP, o pesquisador precisa buscar a neutralidade sob o risco de ameaçar a validade da pesquisa. Para tanto, é necessário se ater à teoria, seguir um protocolo de pesquisa bem definido previamente e produzir um relato objetivo a partir da triangulação de múltiplas fontes de evidência [Yin, 2001]. 
No ECI, entretanto, assume-se que é impossível o pesquisador ser neutro diante de interações com outras pessoas. Ainda assim, o pesquisador pode buscar um distanciamento crítico, ouvindo diferentes pontos de vista sobre o caso e refletindo sobre os achados do campo e a teoria estabelecida [Walsham, 2006]. Para tanto, o pesquisador pode construir o conhecimento de maneira dialógica [Klein e Myers, 1999]. Em outras palavras, o pesquisador deve realizar diversas visitas de campo e consultas à literatura e, assim, promover um diálogo entre a teoria e o campo de pesquisa. Desta forma, irá abarcar visões distintas sobre o caso e obterá múltiplas interpretações do seu ECI [Klein e Myers, 1999]. O princípio da suspeição requer sensibilidade do pesquisador a fim de identificar possíveis "vieses" e "distorções" sistemáticas nas narrativas coletadas dos participantes [Klein e Myers, 1999]. As diferenças entre os ECP e os ECI também aparecem nos critérios de aferição de qualidade de uma pesquisa. Os ECP são validados por critérios mais objetivos, por exemplo, validade interna, validade do construto, validade externa e confiabilidade [Yin, 2001]. Tais critérios são muito próximos dos critérios usados em experimentos e pesquisa de opinião e visam conferir um caráter de objetividade ao ECP.

Nos ECI, por outro lado, são adotados critérios voltados uma validação subjetiva do caso, por exemplo, contextualização, autenticidade, plausibilidade, múltiplas interpretações e transferibilidade. Tais critérios serão apresentados em detalhes na Seção 3.4 deste capítulo. Cabe aqui afirmar que, de um modo geral, os critérios de validação do ECI se baseiam em um processo subjetivo, no qual o leitor, ao tomar contato com o caso relatado, julga se ele é válido para o seu contexto de leitura.

Além disso, em nossas atividades de pesquisa, docência e prática profissional, nos deparamos com casos. Por exemplo, nas atividades de ensino, utilizamos casos de ensino, ao passo que empresas apresentam seus produtos por meio de casos de sucesso. Contudo, o método de estudo de caso se diferencia destes por alguns elementos.

Os casos de ensino são utilizados como recurso didático para exemplificar situações práticas em que uma determinada técnica, método ou tecnologia foi aplicada por uma organização. Assim, por meio dos casos de ensino, os estudantes podem compreender como um conceito abstrato é aplicado em um contexto prático. Nesse ponto, os casos de ensino se aproximam das pesquisas baseadas em estudos de caso. Contudo, os casos de ensino não possuem o objetivo de produzir novos conhecimentos ou analisar novas técnicas em seus contextos de prática. Isto é, os casos de ensino objetivam exemplificar e disseminar conhecimento prático, enquanto as pesquisas de estudo de caso têm por objetivo produzir novos conhecimentos.

O outro tipo de caso, o caso ilustrativo, também chamado de caso de sucesso ou caso de fracasso, é aquele utilizado por empresas para ilustrarem seus produtos e tecnologias em situações práticas. Nesse caso, as empresas relatam um caso de uma determinada tecnologia em um contexto prático de modo a evidenciar os potenciais benefícios da tecnologia e mostrar sua aplicabilidade a possíveis clientes. De maneira análoga há também os casos de fracasso, os quais relatam um fracasso de modo a se tirar lições aprendidas com uma situação que não ocorreu conforme planejada. Assim como o caso de ensino, o caso ilustrativo se aproxima das pesquisas de estudo de caso ao relatar uma situação de uso de SI em seu contexto prático. Contudo, os casos ilustrativos não passaram pelo processo de validação científica, por exemplo, revisão por pares e debates em bancas e congressos, nem necessariamente se baseiam na 
literatura ou nas técnicas de coleta e análise de dados aceitas pela comunidade científica.

Os casos de ensino e casos ilustrativos possuem importantes funções didáticas, mas não podem ser considerados estudos de caso sob um olhar científico. Uma pesquisa baseada em estudo de caso, diferente de um caso ilustrativo, deve observar critérios de qualidade e rigor científico, dialogar com a literatura prévia e se submeter ao escrutínio da comunidade científica. Além disso, no estudo de caso, o pesquisador deve buscar um distanciamento crítico [Walsham, 2006] para analisar o caso sem ser capturado por ele e, assim, apresentar suas teorizações de forma independente de outros interesses.

\subsubsection{Alguns exemplos de Estudos de Caso Interpretativos em SI}

Nesta seção, apresentamos brevemente três exemplos de ECI em SI. Com isso, esperamos evidenciar as características desse paradigma de pesquisa. Além disso, utilizamos esses exemplos para explicar os conceitos que serão apresentados nas seções seguintes.

No trabalho "Examining technology, structure and identity during an Enterprise System implementation”, Alvarez (2008) realizou um estudo longitudinal sobre a implementação e uso de um SI para gestão acadêmica em uma universidade. Este estudo buscou contribuir com a literatura ao mostrar como um sistema pode ser bem recebido por algumas pessoas, enquanto é contestado por outras. A contestação gera ansiedade, tensão e incerteza no ambiente de trabalho. Assim, a autora buscou trazer novas ideias para entendimento sobre como um SI é recebido em uma organização e suas consequências para a estrutura, relações de poder e identidade.

A análise crítica do discurso foi selecionada como a perspectiva teórica usada para identificar interesses concorrentes e investimentos institucionais e como estes se manifestam por meio da linguagem falada pelos indivíduos. Quanto ao método, a pesquisadora realizou entrevistas semiestruturadas e trabalhou iterativamente ao refinar as questões após várias entrevistas iniciais. A pesquisadora estava envolvida em todas as iterações para se tornar "intimamente familiar" com os dados [Eisenhardt, 1989].

O estudo de Alvarez (2008) analisou os dados dos estágios posteriores da implementação do sistema, no momento em que os clientes estão usando o sistema nas práticas de trabalho diárias. Os representantes de agendamento (scheduling representatives ou $S R S$ ) supervisionavam o planejamento de aulas dos estudantes e informalmente orientavam os alunos durantes seu percurso acadêmico.

As descobertas de Alvarez (2008) mostram que, após a chegada do SI na universidade, a identidade e o controle dos SR sobre as atividades da universidade foram desafiados, o que gerou resistência por parte dos SR. Os funcionários não foram simpáticos ou ignoraram a perda de controle e a sensação de desqualificação que experimentaram. Atos de resistência por parte dos SR produziram adaptações imprevistas da tecnologia e, de alguma forma, mitigaram uma tecnologia que muitos SR sentiam ter despojado de sua autonomia e identidade profissional.

O estudo de Alvarez (2008) forneceu contribuições sobre a transformação organizacional que não estariam disponíveis se tivéssemos simplesmente examinado um momento específico no tempo. O estudo temporal mostrou mudanças sociais complexas e um tanto imprevisíveis que ocorrem em uma organização. Este estudo também 
mostrou que a TI é um fenômeno social e imaginário complexo, e contestado tanto quanto é um fenômeno técnico.

De certo modo, este estudo mostra como a tecnologia, estrutura e identidade são múltiplas constitutivas. No passado, os SI legados eram construídos para apoiar ou aprimorar as práticas existentes. Desenvolvedores de sistemas trabalharam com a equipe para identificar requisitos de informação, desenvolver especificações, codificar, testar e implementar sistemas. O SI empresarial é apresentado como uma forma de permitir (ou mesmo exigir de imediato) que uma organização altere fundamentalmente seus processos de negócios para se adequar às melhores práticas incorporadas na tecnologia, pois este tipo de SI vem pronto para organização. Portanto, segue-se que uma implementação "bem-sucedida" de um SI empresarial exigirá a mudança não apenas das estruturas existentes, mas também das identidades profissionais [Alvarez, 2008].

Já o ECI de Avgerou et al. (2009) - "Interpreting the Trustworthiness of Government Mediated by Information and Communication Technology: Lessons from Electronic Voting in Brazil" - foi realizado baseado no uso das tecnologias para apoiar o processo de votação eletrônica no Brasil. Assim, os autores formularam o estudo para investigar o "a crença de cidadãos de que agências governamentais são confiáveis e buscou investigar como um serviço de governo mediado por tecnologia, como o voto eletrônico, estava implicado nesta crença". Isto é particularmente pertinente para a questão da confiança dos cidadãos no governo democrático, porque diz respeito a uma das instituições mais fundamentais da democracia e é usada por todos os cidadãos maiores de 18 anos. O estudo visava determinar o potencial de projetos de governo eletrônico patrocinados na região latino-americana para impactar os cidadãos a confiar em seus governos.

O embasamento teórico desta pesquisa foi a relação entre confiança e confiabilidade. O conceito de confiabilidade se refere às propriedades pelas quais uma entidade confiável (se outra pessoa ou uma instituição) atende aos interesses daquele que confia, enquanto a confiança reflete as crenças ou percepções do cidadão sobre a confiabilidade daquela entidade. A relação entre confiabilidade e confiança tem recebido grande atenção em estudos de confiança em democracias avançadas, onde pesquisas mostram suspeitas generalizadas do desempenho de quase todas as instituições estabelecidas, como escolas e sistemas de saúde. A confiança no governo é distinta da confiança em determinados indivíduos que ocupam posições no governo e na administração [Avgerou et al., 2009].

O estudo teve como objetivo traçar a construção do sistema de e-votações, bem como as dimensões organizacionais, sociais e políticas de seu contexto; produzir uma descrição do processo de eleições; e identificar percepções e crenças sobre a confiabilidade dos sistemas de tecnologia, o serviço de eleições eletrônicas e as eleições como uma instituição de governo democrático. A coleta de dados foi realizada por meio de entrevista aos gerentes de projetos e desenvolvedores dos SI que suportam a votação eletrônica, além de análise de documentações técnicas utilizados nas organizações responsáveis pelas eleições no Governo Federal. Buscou-se entender o contexto institucional das eleições e o processo das eleições. Por fim, entrevistou-se também eleitores para se obter opiniões e sentimentos sobre o sistema de voto eletrônico, a condução de eleições e a condução da política no Brasil [Avgerou et al., 2009]. Como conclusão, o estudo de Avgerou et al. (2009) mostrou que se encontraram evidências de 
que o sistema de votação do Brasil é amplamente usado e apreciado, e que os resultados das eleições que ele produz são, com poucas exceções, aceitos como o agregado correto dos votos reais dos cidadãos individuais.

Porém, Avgerou et al. (2009) traz algumas limitações no seu estudo. Primeiramente diz que a crença na confiabilidade é um conceito cognitivo, que não consegue captar com precisão os sentimentos e a atitude comportamental dos cidadãos em relação ao governo democrático. Um estudo da confiança terá de ir além do rastreamento de percepções e crenças e investigar as ações políticas dos cidadãos. Em segundo lugar, não foram capazes de examinar se e como a crença de confiabilidade dos serviços de uma agência aumenta a crença de confiabilidade do governo democrático. Encontramos algumas indicações de cautela quanto à suposição de possibilidade de tal aumento. Simplificando, a percepção de que as eleições são confiáveis pode pesar pouco para as categorias da população pobre que não esperam que um governo democraticamente eleito melhore suas condições de vida.

Por fim, o ECI de Chua e Myers (2017) - "Social control in information systems development: a negotiated order perspective" - descreve um ECI sobre relação entre cliente e fornecedor de tecnologia no departamento de SI de um grande distribuidor agrícola. Os autores, ao investigarem o controle em projetos de SI: "proveram um entendimento mais sutil das forças sociais que afetam o controle nos sistemas de informação" (tradução nossa). Esse argumento buscou responder a questão até então não resolvida "como forças sociais e ordens negociadas afetam a forma que clientes asseguram que fornecedores desempenham os níveis de satisfação definidos".

De acordo com o estudo, os SI são fundamentais para as operações do cliente e incluem sistemas para planejar rotas de veículos para coleta de fazendas, testar a qualidade do produto, armazenar e gerenciar o comércio global. A subsidiária da Nova Zelândia gerencia as operações e os aplicativos em andamento do cliente, incluindo aplicativos personalizados e grandes sistemas corporativos. Neste contexto, este estudo de caso foi dividido em quatro situações sobre: tabelas de preços, processos de controle da central de ajuda, reportar uma situação de crise e termos do contrato.

O embasamento teórico teve como teorias a Teoria do Controle e a Teoria da Ordem Negociada. A Teoria do Controle se concentra em motivar os indivíduos a agirem de acordo com os objetivos organizacionais. A Teoria da Ordem Negociada ajuda a esclarecer a dinâmica do controle da SI na prática e a explicar consequências não intencionais. Ela destaca que a estrutura, a cognição compartilhada e as relações que os controladores constroem o capital social e constituem o contexto social no qual as estruturas sociais dos controles são executadas [Chua e Myers, 2017].

Este ECI baseou-se nas lentes da Teoria da Ordem Negociada para estudar o controle do caso, abrangendo o contexto, controle, controlador e negociação. Para obtenção dos dados, os autores realizaram entrevistas que foram gravadas, ou apenas tomaram notas, além de terem tido acesso a relatórios, reuniões e partes do contrato relacionadas à governança de fornecedores. Ainda obtiveram dados de várias fontes, incluindo o cliente e o fornecedor. Pararam de solicitar entrevistas depois que não estavam gerando novas descobertas, controles ou insights, ou seja, quando a saturação teórica era alcançada [Chua e Myers, 2017].

Alguns dos resultados e conclusões deste estudo foi que o comportamento humano não pode ser controlado muito bem aplicando a Teoria de Controle em sua 
forma atual (essa teoria tem aplicabilidade limitada para o desenvolvimento e operações de SI). Os controles resultam de negociações entre controladores e controles dentro de um contexto particular. Uma contribuição da pesquisa é ver os controles como estruturas sociais ligadas ao contexto social em que são encenadas. Os controles são moldados e reapropriados dentro deste contexto. Os controles têm consequências intencionais e não intencionais, e outras forças não incluídas na teoria de controle modelam a execução de controle por parte de um controlador. Identificamos algumas das forças sociais que afetam o controlador e o controlando ao executar os controles. Essas forças ajudam a explicar por que os controles resultam diferentes dos esperados pela teoria de controle. Os controles podem atribuir os significados errados aos controles ou responder de maneiras que alteram a eficácia dos controles. A perspectiva da ordem negociada reconhece que as forças sociais operam em um contexto social que molda ambos os atores; o controlador e o controlado. Especificamente, sugere que um controlador não pode executar unilateralmente o controle. Em vez disso, o controlador e o controlando devem negociar o controle. Se nenhuma negociação explícita ocorrer, haverá uma negociação implícita (e.g. a criação de estruturas alternativas), ou alguma forma de disfunção de controle surgirá. Ver o controle como resultado de ordens negociadas entre controladores e controles contribui para a teoria do controle, sugerindo que, na prática, a negociação, a modelagem e a reapropriação são necessárias para a execução bem-sucedida do controle [Chua e Myers, 2017].

A fim de sintetizar esses três casos e reforçar as características dos ECI apresentamos a Tabela 3.2 com os elementos das pesquisas acima descritas.

Tabela 3.2 - Síntese dos exemplos de Estudos de Caso Interpretativos.

\begin{tabular}{|c|c|c|c|}
\hline & Alvarez (2008) & Avgerou et al. (2009) & $\begin{array}{c}\text { Chua e Myers } \\
\text { (2017) }\end{array}$ \\
\hline Objetivo & $\begin{array}{c}\text { Aprimorar } \\
\text { entendimento sobre } \\
\text { como o SI é recebido } \\
\text { em uma organização e } \\
\text { as consequências para } \\
\text { estrutura, relações de } \\
\text { poder e identidade. }\end{array}$ & $\begin{array}{c}\text { Investigar como um } \\
\text { serviço de governo } \\
\text { mediado por } \\
\text { tecnologia estava } \\
\text { implicado na } \\
\text { confiança dos } \\
\text { cidadãos em relação } \\
\text { às instituições } \\
\text { governamentais. } \\
\end{array}$ & $\begin{array}{c}\text { Prover } \\
\text { entendimento mais } \\
\text { sutil das forças } \\
\text { sociais que afetam } \\
\text { o controle nos SI. }\end{array}$ \\
\hline Local da Pesquisa & Universidade & Brasil & $\begin{array}{l}\text { Departamento de SI } \\
\text { de uma empresa }\end{array}$ \\
\hline Caso & $\begin{array}{c}\text { SI para gestão } \\
\text { acadêmica em uma } \\
\text { universidade }\end{array}$ & $\begin{array}{c}\text { Voto eletrônico no } \\
\text { Brasil }\end{array}$ & $\begin{array}{l}\text { Relação cliente- } \\
\text { fornecedor em uma } \\
\text { empresa }\end{array}$ \\
\hline Referencial Teórico & $\begin{array}{l}\text { Análise Crítica de } \\
\text { Discurso }\end{array}$ & $\begin{array}{l}\text { Teoria de confiança e } \\
\text { confiabilidade }\end{array}$ & $\begin{array}{l}\text { Teoria do Controle } \\
\text { e da Ordem } \\
\text { Negociada }\end{array}$ \\
\hline Coleta de Dados & $\begin{array}{l}\text { Entrevistas, } \\
\text { refinamento dos dados }\end{array}$ & $\begin{array}{l}\text { Entrevistas e análise } \\
\text { de documentos }\end{array}$ & $\begin{array}{c}\text { Entrevistas, } \\
\text { reuniões e análise } \\
\text { de relatórios }\end{array}$ \\
\hline Espaço Temporal & $\begin{array}{c}\text { Implantação/Uso do SI } \\
(1996-1998 / 2002-03)\end{array}$ & $\begin{array}{l}\text { Preparação/realização } \\
\text { eleições:2004-2006 }\end{array}$ & $\begin{array}{c}\text { Período do } \\
\text { Contrato (5 anos) } \\
\end{array}$ \\
\hline
\end{tabular}


Esses são apenas alguns exemplos de ECI em SI. Se desejar se aprofundar no assunto, por favor consulte as referências. Outros exemplos podem ser encontrados em periódicos e livros da área. Na Seção 3.4 utilizamos estes exemplos e os correlacionamos com os princípios de validade que devem ser considerados em um ECI. Nós nos aprofundaremos nas características do ECI na próxima seção.

\subsection{Critérios de Qualidade de Estudos de Caso Interpretativos em SI}

O paradigma interpretativo possui princípios e técnicas que permitem assegurar a validade de um ECI, norteando os procedimentos de coleta e análise dos dados de modo que a pesquisa tenha validade e seja reconhecida pela comunidade científica.

Explicamos os sete princípios de condução de pesquisas inspiradas pelo paradigma interpretativo elencados por Klein e Myers $(1999)^{8}$, que se baseiam principalmente no princípio da hermenêutica. Cabe aqui ressaltar que os sete princípios não são como regras de conduta burocráticas, porque a aplicação de um ou mais deles ainda requer considerável pensamento criativo. O uso da palavra "princípios", portanto, protege contra a ideia de que seu uso é obrigatório; em vez disso, cabe aos autores, revisores e editores exercerem o seu julgamento ao decidirem se, como e quais princípios devem ser aplicados e apropriados em qualquer projeto de pesquisa. No entanto, isso não significa que se deve escolher de forma arbitrária alguns princípios e ignorando outros, pois os princípios são, pelo menos até certo ponto, interdependentes.

Além destes, abordamos também os princípios oriundos de Golden-Biddle e Locke (1993), trazidos em uma releitura estendida e abrangente por Pozzebon (2004), que tem sido usada para validar ECI. A Tabela 3.3 traz um resumo destes princípios e a fase da pesquisa em que os mesmos deverão ser observados.

Tabela 3.3. - Princípios de Validade para o Estudo de Caso Interpretativo. Adaptado de Klein and Myers (1999) e Pozzebon (2004).

\begin{tabular}{|l|l|l|}
\hline \multicolumn{1}{|c|}{ Critérios de Validade } & \multicolumn{1}{|c|}{ Descrição } & Fase de Pesquisa \\
\hline contextualização & entendimento: fundo histórico e social & projeto de pesquisa \\
\hline $\begin{array}{l}\text { interação - pesquisador } \\
\text { e sujeito }\end{array}$ & $\begin{array}{l}\text { reflexão crítica: como os dados são } \\
\text { construídos - pesquisador e sujeito }\end{array}$ & coleta/análise dados \\
\hline $\begin{array}{l}\text { abstração, } \\
\text { generalização e } \\
\text { plausibilidade }\end{array}$ & $\begin{array}{l}\text { interpretação dos dados através de uma } \\
\text { teoria e verificando o sentido }\end{array}$ & coleta/análise dados \\
\hline $\begin{array}{l}\text { raciocínio dialógico e } \\
\text { reflexividade }\end{array}$ & $\begin{array}{l}\text { expôr preconceitos do pesquisador, } \\
\text { confrontando com a pesquisa e fazer } \\
\text { reflexão na escrita do texto }\end{array}$ & $\begin{array}{l}\text { projeto de pesquisa e } \\
\text { análise dados }\end{array}$ \\
\hline múltiplas interpretações & $\begin{array}{l}\text { diferenciar interpretações dos } \\
\text { participantes }\end{array}$ & análise dados \\
\hline suspeita e autenticidade & identificar distorções entre participantes & coleta/análise dados \\
\hline
\end{tabular}

\footnotetext{
${ }^{8}$ Klein e Myers (1999) apresentam critérios para pesquisas interpretativas, os quais podem ser usados outros métodos além dos ECI, como, etnografia e pesquisa-ação. Para fins didáticos e dado o enfoque deste capítulo, vamos tratar desses critérios apenas nos ECI.
} 
Quanto a exemplos reais de estudos de caso em SI para analisarmos como se aplicaram os princípios de validade, ao longo desta seção utilizamos os estudos exemplificados na Seção 3.3.

\subsubsection{Contextualização}

O critério da contextualização requer que o assunto seja definido em seu contexto social e histórico para que o público-alvo possa ver como a situação atual sob investigação emergiu. O espírito em que isso é feito difere de um relato positivista da história. Os pesquisadores inspirados pelo paradigma interpretativo argumentam que as organizações não são estáticas e que as relações entre pessoas, organizações e tecnologia não são fixas, mas estão em constante mudança [Klein e Myers, 1999].

Alvarez (2008) utiliza claramente este princípio quando mostra que o artigo faz parte de um estudo longitudinal da implementação de um sistema empresarial e traz na introdução o contexto do surgimento do sistema empresarial nas empresas. Alvarez (2008) nos mostra que, na última década anterior à pesquisa, as organizações passaram a implementar uma classe de software empacotado chamada sistema empresarial. A popularidade deste software era evidenciada por seu crescimento explosivo nos últimos anos anteriores. Além disso, situa sua pesquisa que contribui para investigar a relação entre sistema empresarial, estruturas organizacionais e identidade ao longo de um período de tempo.

Já o trabalho de Avgerou et al. (2009) em seu artigo sobre votação eletrônica no Brasil, possui uma seção exclusiva sobre o contexto na qual a pesquisa foi realizada. Assim, contextualiza que o contexto institucional brasileiro é uma comunidade pública e federativa. A autoridade responsável pela condução dos assuntos eleitorais é o Tribunal Superior Eleitoral (TSE) e explica todo o funcionamento do trâmite do voto eletrônico brasileiro.

Chua e Myers (2017), em seu estudo sobre controle social no desenvolvimento de sistemas, traz o contexto inicial do estudo. Foi explorado o contexto social, organizacional e interorganizacional mais amplo que circundava o controle. Isso incluiu a história de cada organização e suas histórias conjuntas e as experiências anteriores de controladores e controles.

Com estes exemplos, podemos perceber que o princípio da contextualização em um ECI é de suma importância para contextualizar o público-alvo da pesquisa e trazer entendimento amplo do contexto de atuação do SI. Cada SI é único em um determinado contexto de uso, com suas particularidades únicas, meandros, limitações e bricolagem ${ }^{9}$ [Orlikowski e Iacono, 2001; Ciborra, 2002]. Sem a contextualização, torna-se difícil o entendimento da pesquisa que foi realizada.

\footnotetext{
${ }^{9}$ bricolagem - em latim bricola, que significa catapulta. O termo bricolagem significa consertar com a combinação de recursos disponíveis. Esses recursos tornam-se ferramentas e definem descobertas em como se resolver o problema. Significa alavancar o mundo com os recursos definidos pela situação. Com a bricolagem, as práticas e as situações revelam novos usos e aplicações da tecnologia e das coisas [Ciborra, 2002]. Trazendo ao contexto de SI, de acordo com cada contexto, pode haver bricolagem na construção e resolução de problemas no dia a dia dos SI.
} 


\subsubsection{Interação entre pesquisadores e sujeitos}

Este critério exige que o pesquisador coloque a si mesmo e aos sujeitos em uma perspectiva histórica. Na pesquisa social, os "dados" não estão apenas esperando para serem recolhidos, como pedras à beira-mar. Em vez disso, o paradigma interpretativo afirma que os fatos são produzidos como parte e parcela da interação social dos pesquisadores com os participantes [Klein e Myers, 1999]. Para que o pesquisador tenha este entendimento, precisa ir a campo e realizar entrevistas, pois o conhecimento e as descobertas da pesquisa emergem principalmente desta interação de conhecimento que é produzida quando as entrevistas são realizadas.

Alvarez (2008) traz diversos trechos das entrevistas realizadas no estudo dos usuários do sistema empresarial. As entrevistas são fundamentais para realizarmos descobertas e descobrir o que se passa na mente do sujeito e como ele percebe o SI e todo contexto.

Segundo Yin $(2001)^{10}$, as entrevistas para o estudo de caso devem ser conduzidas de forma espontânea. Walsham (1995) realiza um desenvolvimento teórico de Yin (2001) trazendo para a perspectiva do paradigma interpretativo. Nos ECI, as entrevistas se tornam fundamentais e são a principal fonte de dados, pois é a partir deste método que o pesquisador pode acessar melhor as interpretações que os participantes têm sobre as ações e eventos que possuem ou estão ocorrendo (e suas opiniões). Uma questão-chave para todos os entrevistadores é o equilíbrio que deve ser adotado por eles entre a passividade e o excesso de direção que se dá à entrevista. Se o entrevistador dirige a entrevista muito de perto e se recusa a permitir que os entrevistados expressem seus próprios pontos de vista, então os dados obtidos perderão muito da riqueza de interpretação que é a matéria-prima da pesquisa. Por outro lado, se o entrevistador for muito passivo, o entrevistado pode concluir que ele não está interessado no que está sendo dito. O importante é captar da melhor maneira as interpretações das pessoas [Walsham, 1995].

Quanto ao registro da entrevista, esse é um ponto importante a ser citado. Muitos entrevistados não ficam confortáveis com o uso de gravadores. Sendo assim, devemos buscar fazer notas, verificando termos chaves e importantes que foram utilizados pelo entrevistado, que podem traduzir alguma teoria que podemos identificar, corroborar e usar na nossa pesquisa. Uma boa sugestão é que, tão logo termine a entrevista, as notas sejam passadas a limpo e o registro seja validado, por escrito, com o entrevistado. Muitas vezes, ainda há possibilidade de correção de detalhes que talvez o pesquisador possa não ter captado no momento da entrevista.

Antonio et al. (2018) explicam que, muitas vezes, a 'história a ser contada' e os meandros de um SI não estão registrados em documentos. Por isso, é muito importante extrair a informação por meio de entrevistas, buscando várias pessoas como referência e fazendo com que as informações sejam corroboradas por outras pessoas da mesma organização ou de outras organizações que possuem relação com aquele SI que está sendo estudado.

${ }^{10}$ Citamos Yin (2001) por seu efeito didático. Para o desenvolvimento teórico aplicado a ECI, que é o foco deste capítulo, utilizamos argumentações de autores que pesquisam e são referências no paradigma interpretativo, tais como Walsham (1995), Golden-Biddle and Locke (1993), Klein e Myers (1999), e Pozzebon (2004). 


\subsubsection{Abstração, Generalização e Plausibilidade}

Neste critério, agregamos a visão de Walsham (1995), que argumenta que existem quatro tipos de generalizações de ECI: o desenvolvimento de conceitos, a geração de teoria, o desenho de implicações específicas, e a contribuição de descobertas à comunidade científica. Klein e Myers (1999) ressaltam que a teoria desempenha um papel crucial nas pesquisas conduzidas sob o paradigma interpretativo. É importante que abstrações e generalizações teóricas sejam cuidadosamente relacionadas aos detalhes do estudo de campo, uma vez que foram experimentadas ou coletadas pelo pesquisador. Isso é para que os leitores possam acompanhar como o pesquisador chegou às suas percepções teóricas. Para utilizar os critérios da abstração e generalização teóricas, no estudo de Alvarez (2008), foi utilizada a Teoria de Análise Crítica do Discurso para analisar os dados das entrevistas. No estudo de Avgerou et al. (2009) foi utilizada a Teoria da Confiança e Confiabilidade para analisar a confiança dos cidadãos brasileiros no sistema de votação no contexto estudado. Por fim, no estudo de Chua e Myers (2017) se utilizou a Teoria do Controle e da Ordem Negociada, para relacionar os dados entre controlador e controlado.

Para demonstrar o princípio da plausibilidade, os pesquisadores devem se preocupar com dois componentes interconectados. Primeiro, os pesquisadores precisam mostrar que sua pesquisa faz sentido, o que significa lidar com preocupações comuns, estabelecendo conexões com os antecedentes e experiências pessoais e disciplinares de seus leitores. Segundo mostrar que há uma contribuição para o campo é um dos aspectos mais importantes a serem considerados. $\mathrm{O}$ valor de qualquer pesquisa empírica depende da medida em que o autor nos diz algo novo e relevante [Pozzebon, 2004].

Um ECI precisa mostrar que faz sentido e qual a sua contribuição para um campo de pesquisa. Alvarez (2008), em seu artigo, mostra que sua pesquisa faz sentido na importância de compreender as consequências organizacionais da implementação de sistemas grandes e complexos. Traz ainda o seu objetivo ao introduzir o tópico de investigação, que é a de investigar a relação entre sistemas empresariais, estruturas organizacionais e identidade ao longo de um período de tempo longitudinal. Avgerou et al. (2009) mostrou que havia propensão dos cidadãos brasileiros a receber iniciativas governamentais para a inovação em serviços de governo eletrônico, como o sistema de votação brasileiro. Por fim, Chua e Myers (2017) mostraram que os controles resultam de negociações entre controladores e controlados dentro de um contexto particular. Uma contribuição deste artigo à comunidade científica é observar os controles como estruturas sociais ligadas ao contexto social em que são inseridas. A escolha da teoria e analisar os dados a partir dela é um critério fundamental para um bom ECI.

\subsubsection{Raciocínio Dialógico e Reflexividade}

Esse critério exige que o pesquisador enfrente os seus preconceitos (que orientaram o desenho original da pesquisa, ou seja, as lentes originais) com os dados que emergem a partir do processo de pesquisa.

Klein e Myers (1999), nos mostram que o pesquisador deve ter sensibilidade a possíveis contradições entre os preconceitos teóricos que orientam o desenho da pesquisa e as descobertas reais ("a história que os dados contam") com os subsequentes ciclos de revisão a cada coleta de dados. Ou seja, o pesquisador não deve "emplacar" a teoria sobre o campo de modo a buscar dados que apenas confirmem a teoria empregada na pesquisa. $O$ pesquisador deve ficar atento às diferenças observadas no campo de 
pesquisa e abarcar elementos que refinam, estendam ou contradigam a teoria prévia de modo a aprimorar o conhecimento sobre o assunto pesquisado. Esse foi o caso de Alvarez (2008), que revelou que seus achados foram inesperados. Isso mostra que a autora não procurou apenas corroborar uma posição inicial. Ao invés disso, realizou uma análise profunda dos elementos que emergiram no estudo de caso e não teve preconceitos a estes.

Avgerou et al. (2009), na conclusão do seu estudo, admite que a crença na confiabilidade é um conceito cognitivo e que não consegue captar com precisão os sentimentos e a atitude comportamental dos cidadãos em relação ao governo democrático. Um estudo da confiança terá de ir além do rastreamento de percepções e crenças e investigar as ações políticas dos cidadãos. Isto foi colocado como uma limitação na pesquisa.

Um ponto importante é o pesquisador tornar a base intelectual histórica da pesquisa o mais transparente possível para o leitor e para si próprio [Klein and Myers, 1999]. Ou seja, o pesquisador deve apresentar em seus relatos de pesquisa as suas preferências teóricas e a sua posição no campo de pesquisa, de modo a permitir ao leitor entender como as escolhas da pesquisa foram feitas. Importante ressaltarmos que o pesquisador está constantemente conversando com o campo de pesquisa. O pesquisador vai mudando seus conceitos, voltando a campo algumas vezes e realizando novas análises; com isso, vai evoluindo e modificando a pesquisa.

A reflexividade implica em se atentar sobre como os textos são escritos e como a pesquisa é comunicada [Alvesson e Skoldberg, 2000]. O nível de interpretação que cada trabalho de pesquisa empírica alcança depende, essencialmente, das premissas e propósitos de cada pesquisador [Pozzebon, 2004]. No nosso campo de SI, Pozzebon (2004) mostra que a reflexividade ainda não recebe atenção nas nossas pesquisas. Uma pesquisa reflexiva deve ir além da interação entre pesquisador e sujeito e examinar a relação entre pesquisadores e a rede de pesquisa da qual fazem parte. Schultze (2000) definiu a dimensão reflexiva de seu trabalho com um elemento chamado escrita autoreveladora. Um texto auto-revelador exige um autor personalizado, o uso de pronomes pessoais para destacar consistentemente o ponto de vista representado e a construção do pesquisador como um indivíduo razoável, porém falível, com o qual o público pode se identificar. Alvarez (2008), Avgerou et al. (2009) e Chua e Myers (2017), utilizaram o pronome pessoal "nós" em diversos momentos do artigo e isso mostra reflexividade na pesquisa.

\subsubsection{Múltiplas interpretações}

Este princípio requer que o pesquisador examine as influências que o contexto social tem sobre as ações em estudo ao procurar e documentar vários pontos de vista, juntamente com as suas respectivas razões. A análise de razões pode incluir os conflitos relacionados ao poder, economia ou valores. Além disso, o pesquisador deve enfrentar as contradições potencialmente inerentes aos vários pontos de vista uns com os outros e rever o seu entendimento em conformidade [Klein and Myers, 1999].

Antonio et al. (2018) argumentam que o pesquisador não deve utilizar estudo de caso apenas para comprovar uma posição preconcebida. Os pesquisadores geralmente estão propensos a esse problema porque eles devem compreender as questões e agir com discrição. O pesquisador deve estar aberto aos resultados da pesquisa, mesmo se não for o resultado que este estava imaginando de início com o estudo de caso. Um ECI 
deve abarcar diferentes pontos de vista e as múltiplas interpretações, caso estes ocorram, e analisar a interação do contexto sobre eles.

No artigo de Chua e Myers (2017), cada uma das negociações apresentadas trouxeram diferentes perspectivas e todas foram explicitadas e contempladas no artigo. Com isso, descobriram na teorização sobre estruturas sociais que, além da intenção do controlador, outras forças moldam a execução e o comportamento do controle. Essas forças são o contexto, a interpretação do controlado e do controlador, uma negociação entre o controlado e o controlador e, finalmente, o próprio controle. Nossas descobertas apoiam nossa teorização, mas também as amplia com novos insights. Se não tivessem abarcado os diversos pontos de vista emergidos nos exemplos da pesquisa, não teriam tido outros insights sobre a teoria de controle social. O princípio das múltiplas interpretações traz confiabilidade à pesquisa.

\subsubsection{Suspeita e Autenticidade}

Quanto ao princípio da suspeita, o pesquisador deve estar sempre com o pensamento crítico atento para descoberta de falsos preconceitos na pesquisa por ele e pelos atores envolvidos [Klein and Myers, 1999]. No que tange ao princípio da autenticidade, significa ser genuíno para a experiência de campo como resultado de estar no campo de pesquisa [Golden-Biddle e Locke, 1993]. O pesquisador deve realizar o registro de pesquisa de forma fidedigna, registrando todos os acontecimentos do campo de pesquisa sem ocultar nada.

Nos estudos de Alvarez (2008) e Chua e Myers (2017), ambos os grupos de pesquisadores foram ao campo de pesquisa e registraram as evidências nos artigos elaborados. Foram trazidos trechos das entrevistas realizadas e um contexto detalhado de onde foi realizada a pesquisa de campo.

A vivência do pesquisador no campo de pesquisa e estar presente na organização a ser pesquisada são pontos importantes de serem observado na autenticidade. A análise de documentos de arquivo nos ECI também demonstra esse princípio [Pozzebon, 2004].

Antonio et al. (2018) nos mostram que, quanto aos documentos relativos ao estudo de caso, estes podem ser buscados dentro da organização que aquele SI está inserido, bem como por estudos já realizados de outros pesquisadores, trazendo estatísticas e o contexto histórico à época que aquele SI foi criado. Sobre os registros em arquivos, tais como dados de um SI e arquitetura utilizada, número de usuários do sistema, dados estatísticos oriundos de levantamentos, dentre outros, podem ser úteis se combinados a outras evidências ao se montar o estudo de caso.

Devemos ter em mente, após termos as evidências dos dados que foram coletados, que se deve desenvolver linhas convergentes de investigação. Assim, qualquer descoberta ou conclusão em um ECI provavelmente será muito mais convincente e acurada caso se baseie em várias fontes distintas de informação, obedecendo a um estilo corroborativo de pesquisa. Desta forma o pesquisador conseguirá demonstrar autenticidade na pesquisa conduzida sob o paradigma interpretativo. 


\subsection{Realizando um Estudo de Caso Interpretativo}

Após termos visto na Seção 3.4 como critérios de qualidade foram utilizados em ECI publicados por pesquisadores de referência nesta metodologia, vamos trazer sugestões práticas para realizar o ECI.

Walsham (2006) argumenta que o primeiro elemento para se realizar ECI é o pesquisador escolher qual é seu 'estilo em campo'. O pesquisador pode ser "externo", realizando um estudo principalmente por meio de entrevistas formais, sem envolvimento direto em ações no campo, ou fornecendo feedback significativo aos participantes de campo. Ou pode ser um pesquisador "envolvido" como um observador participante ou pesquisador de ação. Este espectro muda com frequência ao longo do tempo de pesquisa [Walsham, 2006] e devem ser observadas as vantagens e desvantagens de cada estilo, ainda de acordo com o nível de acesso que o pesquisador tem na organização.

O segundo elemento para o pesquisador realizar ECI é a escolha da teoria. A teoria pode ser escolhida e utilizada dependendo da etapa da pesquisa. Além disso, a teoria pode ser usada de maneira mais leve ou mais rígida, e ambas as formas têm seus méritos. Mas a escolha da teoria é essencialmente subjetiva. A resposta está nas próprias experiências, antecedentes e interesses do pesquisador. Eles escolhem uma teoria em particular porque "falaram" com eles. Walsham (2006) traz alguns itens para nortear esta escolha, conforme segue: (1) A teoria deve ser escolhida se fizer sentido para o pesquisador; (2) o pesquisador deve estar engajado na teoria escolhida e não deve se fixar em apenas uma teoria e depois não ler mais nada; (3) o pesquisador não deve deixar a geração da teoria até o final do seu estudo; (4) não descarte o valor de uma teoria até que você tenha lido sobre ela com alguma profundidade e (5) finalmente, leia amplamente sobre diferentes teorias, pois isso oferecerá a você uma base mais ampla para escolher e maior probabilidade de encontrar uma teoria ou teorias que o inspirem, além de permitir que você obtenha bons insights a partir de seus dados de campo.

O terceiro elemento para o pesquisador realizar ECI, conforme Walsham (2006), é o acesso ao campo de pesquisa. Para isso, um pesquisador precisa ter ou desenvolver duas características: primeiro, melhorar as suas habilidades sociais a fim de conseguir e manter o acesso à organização escolhida; segundo, precisa ter resiliência. A disposição de aceitar "não" como resposta, mais a persistência de tentar em outro lugar, são importantes. Em alguns casos, é possível obter acesso à organização abordando a pesquisa de diferentes ângulos [Walsham, 2006].

O quarto elemento para realizar ECI é, estando em campo, o pesquisador deve ter em mente os critérios de qualidade vistos na Seção 3.4. Interação entre pesquisadores e sujeitos, raciocínio dialógico, suspeição e múltiplas interpretações são alguns dos critérios que devem ser observados de perto pelo pesquisador [Klein e Myers, 1999].

Uma das questões críticas em ECI é como relatar o trabalho de campo. Pesquisadores que realizam estudos segundo o paradigma interpretativo não estão dizendo ao leitor que eles estão relatando fatos; em vez disso, eles estão relatando as suas interpretações sobre as interpretações de outras pessoas. É, portanto, vital, a fim de estabelecer alguma credibilidade para o leitor, que eles descrevam em detalhes como chegaram aos seus 'resultados'. Os relatórios sobre a coleta de dados de campo devem 
incluir detalhes dos locais de pesquisa escolhidos, as razões para essa escolha, o número de pessoas entrevistadas, quais posições hierárquicas ou profissionais ocuparam, que outras fontes de dados foram usadas e em que período a pesquisa foi realizada [Walsham, 2006].

Com relação à análise de dados, o relatório deve incluir como as entrevistas de campo e outros dados foram registrados, como eles foram analisados e como o processo iterativo entre dados de campo e teoria ocorreu e evoluiu ao longo do tempo. Orlikowski (1993) fornece um bom exemplo de relatos cuidadosos sobre os tópicos acima. Maanen (1989) nos lembra que estabelecer validade aos olhos de um leitor é parte da arte da persuasão, e é tanto uma questão de estilo retórico e talento quanto de precisão e cuidado em questões de teoria e método. Deve-se fazer o rascunho da seção metodológica neste estágio inicial. Você se lembrará dos procedimentos metodológicos que utilizou com maior precisão durante esse momento crítico [Walsham, 2006].

Engajamento, instigação e sedução - Essas são características incomuns que existem na metodologia de ECI. Produzir um ECI exige que o pesquisador seja entusiástico em relação à investigação e que deseje transmitir amplamente os resultados obtidos. Um entusiasmo como esse deve permear a investigação inteira e conduzir, de fato, a um bom ECI.

\subsection{Conclusão}

Neste capítulo, apresentamos os paradigmas epistemológicos principais utilizados na pesquisa em SI e aprofundamos nosso conhecimento na metodologia de ECI. Analisamos cada princípio de validade para a pesquisa segundo o paradigma interpretativo e trouxemos exemplos reais de ECI que foram realizados por pesquisadores que são referência no tema. Por fim, elencamos algumas sugestões práticas de estruturação do texto de um ECI conforme Walsham (1995), Klein e Myers (1999) e Pozzebon (2004).

Concluímos que, apesar de desafiador, o método de ECI a ser utilizado em SI pode desvendar diversos elementos que emergem no contexto de produção e uso de SI, os quais não seriam revelados por meio de outra metodologia de pesquisa, enriquecendo assim o corpo teórico em SI. Desta forma, conseguiremos estudar o fenômeno dos SI de uma forma multidisciplinar, indo além do paradigma positivista dominante nas pesquisas em SI e abarcando todos os atores envolvidos na construção de um SI.

A possibilidade de realizar estudos de caso, do ponto de vista profissional, pode ampliar a prática de desenvolvimento e implantação de SI no sentido de permitir ao profissional ou às organizações compreenderem SI em seu contexto, respondendo a perguntas importantes, em geral negligenciadas, a respeito de como e porque SI são utilizados, que significados estabelecem organizacional ou socialmente e que impactos ou resistências geram com seu uso. Todos estes aspectos, quando não estudados pelas organizações, têm o potencial de gerar uma série de problemas comuns relacionados ao desenvolvimento e gestão de SI, como: aplicações que não cumprem seus objetivos esperados quando implantados, desvios e contornos de utilização, gastos de recursos com ajustes e manutenções, descontinuidade, entre tantos outros.

Sendo assim, convidamos a comunidade de pesquisa e prática de SI a praticar a metodologia de ECI e compartilhar suas descobertas, ampliando o conhecimento da área e fortalecendo nossa visão sistêmica e multidisciplinar em SI. 


\section{Referências}

Alvarez, R. (2008) Examining technology, structure and identity during an Enterprise System implementation. Information Systems Journal. Vol. 18, No. 2. pp. 203-224. DOI:https://doi.org/10.1111/j.1365-2575.2007.00286.x.

Alvesson, M.; Skoldberg, K. (2000) Reflexive Methodology: New Vistas for Qualitative Research. London: Sage Publications.

Antonio, N. P., Fornazin, M. \& Araujo, R. M. (2018) Metodologia de Pesquisa de Estudo de Caso em Sistemas de Informação. In: Minicursos da ERSI-RJ 2018 - V Escola Regional de Sistemas de Informação do Rio de Janeiro (1a ed.), França, J. B. e T. França. Sociedade Brasileira de Computação, Nova Friburgo - RJ, pp. 41-67. DOI:https://doi.org/10.5753/sbc.7.2.

Araujo, R., Fornazin, M. \& Pimentel, M. (2017) Uma Análise sobre a Produção de Conhecimento Científico nas Pesquisas Publicadas nos Primeiros 10 anos da iSys (2008-2017) In:iSys: Revista Brasileira de Sistemas de Informação, Vol. 10, No. 4, pp. 45-65.

Araujo, R. M.; Chueri, L. O. V. (2017) In: Pesquisa e Inovação: Visões e Interseções. 1. ed. Rio de Janeiro: Publit Soluções Editoriais. Vol. 1. 296p.

Avgerou, C. (2000) IT and organizational change: an institutionalist perspective. Information Technology \& People, Vol. 13, No. 4, pp. 234-262.

Avgerou, C., Ganzaroli, A., Poulymenakou \& A., Reinhard, N. (2009) Interpreting the Trustworthiness of Government Mediated by Information and Communication Technology: Lessons from Electronic Voting in Brazil. Information Technology Development, Vol. 15, No. 2, pp-133-148. DOI:https://doi.org/10.1002/itdj.20120

Benbasat, I. Goldstein, D. K. \& Mead, M. (1987) The Case Research Strategy in Studies of Information Systems. MIS Quarterly, Vol. 11, No. 3, pp. 369-386. http://www.jstor.org/stable/248684.

Boscarioli, C., Araujo, R. M. \& Maciel, R. S. I (2017) In: GranDSI-BR: Grand Research Challenges in Information Systems in Brazil 2016-2026. $1^{\text {a }}$ ed. Porto Alegre: Sociedade Brasileira de Computação, Vol. 1, 184p. http://www2.sbc.org.br/ce-si/arquivos/GranDSI-BR_Ebook-Final.pdf.

Burrell, G., Morgan, G. (1979) Sociological Paradigms and Organisational Analysis: Elements of the sociology of corporate life, Heinemann, London.

Ciborra, C. (2002) In: The Labyrinths of Information: Challenging The Wisdom of Systems. Oxford University Press 1a ed.

Chua, C. E. H.; Myers, M. D. (2017) Social control in Information Systems Development: a Negotiated Order Perspective. Journal of Information Technology, Vol. 33, No. 3, pp-173-187. DOI:https://doi.org/10.1057/s41265-017-0048-4

Davis, F.D. (1989) Perceived Usefulness, Perceived Ease of Use, and User Acceptance of Information Technology, MIS Quarterly, Vol. 13. DOI: https://doi.org/10.2307/249008. 
Dubé, L.; Paré, G. (2003) Rigor in Information Systems Positivist Case Research: Current Practices, Trends, and Recommendations. MIS Quarterly, Vol. 27, No. 4, p.597. DOI:https://doi.org/10.2307/30036550.

Eisenhardt, K.M. (1989) Building Theories from Case Study. The Academy of Management Review, Vol. 14, No. 4, pp. 532-550. http://www.jstor.org/stable/258557.

Golden-Biddle, K.; Locke, K. (1993) Appealing Work: An Investigation of How Ethnographic Texts Convince, Organization Science, Vol. 4, pp. 595-616.

Hirschheim, R.; Klein, H. K. (1989) Four paradigms of information systems development. Communications of the ACM, Vol. 32, No. 10, pp. 1199-1216.

Hirschheim, R.; Klein, H. K. (2011) Tracing the History of the Information Systems Field. In:Currie, W.; Galliers, R. D. (Ed.). In: The Oxford Handbook of Management Information Systems. Oxford: Oxford University Press, pp. 16-62.

Kitchenham, B. (2006) Evidence-Based Software Engineering and Systematic Literature Reviews. In: Münch J., Vierimaa M. (eds) In: Product-Focused Software Process Improvement. PROFES 2006. Lecture Notes in Computer Science, Vol. 4034. Springer, Berlin, Heidelberg. https://doi.org/10.1007/11767718_3.

Klein, H. K.; Myers, M. D. (1999) A Set of Principles for Conducting and Evaluating Interpretive Field Studies in Information Systems. MIS Quarterly, Vol. 23, No. 1, pp. 67-93. http://www.jstor.org/stable/249410.

Kling, R.; Scacchi, W. (1982) The web of computing: Computer tecnhology as social organization. Adv. Comput, (21), pp-1-90.

Kuhn, T. (1975) A estrutura das revoluções científicas. São Paulo: Perspectiva.

Laudon, K. C.; Laudon, J. P. (2014) In: Sistemas De Informação Gerenciais. São Paulo: Pearson Education.

Latour, B. (2012). In: Ciência Em Ação. Editora Unesp. 2a ed. Tradução de: Science in action: how to follow scientists and engineers through society.

Maanen, V. J. (1989) Some notes on the importance of writing in organization studies. In: The Information Systems Research Challenge (CASH JI and LAWRENCE PR, Eds), Vol.1, Harvard Business School, Boston.

Markus, M. L. Power, politics, and MIS implementation (1983). Communications of the $A C M$, Vol. 26, No. 6, pp. 430-444.

Markus, M. L.; Robey, D. (1988) Information technology and organizational change: causal structure in theory and research. Management Science, Vol. 34, No. 5, pp. 583-598.

Myers, M.D. (1999) Investigating Information Systems with Ethnographic Research. Communications for the Association of Information Systems, Vol. 2, Article 23. https://aisel.aisnet.org/cais/vol2/iss 1/23

Orlikowski W. J.; Baroudi J. (1991) Studying Information Technology in Organizations. Information Systems Research, Vol. 2, No.1, pp-1-28. 
Orlikowski, W. J.; Robey, D. (1991) Information technology and the structuring of organizations. Information systems research, Vol. 2, No. 2, pp.143-169.

Orlikowski W. J. (1993) CASE tools as organizational change: investigating incremental and radical changes in systems development. MIS Quarterly, Vol. 17, No. 3, pp-309-340.

Orlikowski W. J.; Iacono, S. J. (2001) Research Commentary: Desperately Seeking the "IT" in IT Research-A Call to Theorizing the IT Artifact. Information Systems Research, Vol. 12, No. 2, pp.121-134.

Orlikowski, W. J and Scott, S. V. (2008): Sociomateriality: Challenging the Separation of Technology, Work and Organization, The Academy of Management Annals, Vol. 2, No. 1, pp-433-474.

Palvia, P., YK, C. P., Kakhki, M. D., Ghoshal, T., Uppala, V., \& Wang, W. (2017). A decade plus long introspection of research published in Information \& Management. Information \& Management, Vol. 54, No. 2, pp-218-227.

Porra, J.; Hirschheim, R.; Parks, M. S. (2014) The Historical Research Method and Information Systems Research. Journal of the Association for Information Systems, Vol. 15, No. 9, Article 3. https://aisel.aisnet.org/jais/vol15/iss9/3

Pozzebon, M.; Freitas, H. M. R. (1998) Pela Aplicabilidade-com um maior Rigor Científico dos Estudos de Caso em Sistemas de Informação. RAC, Vol. 2, No. 2, pp143-170.

Pozzebon, M. (2004) Conducting and Evaluating Critical Interpretative Research: Examinating Criteria as a Key Component in Building a Research Tradition.

Pimentel, M., Filippo, D., Calvão, L.D., \& Silva, A. R. (2017). "Design Science Research: pesquisa científica para o desenvolvimento de artefatos inovadores". In: Pesquisa e Inovação: visões e interseções. editado por R. M. Araujo \& L. O. V. Chueri. Rio de Janeiro, RJ: Publit.

Runeson, P., Host, M., Rainer, A., \& Regnell, B. (2012). Case study research in software engineering: Guidelines and examples. John Wiley \& Sons.

Recker, J. (2013) Scientific Research in Information Systems - A Beginner's Guide. Springer.

Sayah, S. and Walsham, G. (2006) Scalling of Health Information Systems in India: Challenges and Approaches. Information Technology for Development, Vol. 12, No. 3, pp-185-200.

Schultze, U. (2000) A Confessional Account of an Ethnography about Knowledge Work. MIS Quarterly, Vol. 24, No.1, pp-3-41.

Walsham, G. (1993) Interpreting Information Systems in Organizations, Wiley, Chichester, UK. pp. 4-5.

Walsham, G. (1995) Interpretive case studies in IS research: nature and method. European Journal of Information Systems, Vol. 4, pp.74-81.

Walsham, G. (2006) Doing interpretive research. European Journal of Information Systems, Vol.15, pp.320-330. 
Wazlawick, R. S. (2009) In: Metodologia de Pesquisa para Ciência da Computação Elsevier Editora. São Paulo.

Wohlin, C., Runeson, P., Höst, M., Ohlsson, M. C., Regnell, B., \& Wesslén, A. (2012). Experimentation in software engineering. Springer Science \& Business Media.

Yin, R. K. (2001) In: Estudo de caso: Planejamento e Métodos. trad. Daniel Grassi 2.ed. Porto Alegre: Bookman. 


\section{Autores}

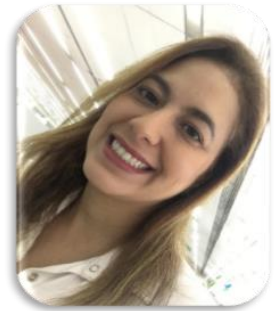

Nadja Piedade de Antonio - http://lattes.cnpq.br/3769571781611695 Mestranda do Programa de Pós-Graduação em Informática da UNIRIO, pesquisando SI Sociais. Possui Bacharelado em Ciências Econômicas pela Universidade Federal Fluminense e pós-graduação em Engenharia de Produção pelo Instituto Nacional de Tecnologia. Atua desde 2007 na área de desenvolvimento de sistemas da CAIXA e, desde 2012, atua como Coordenadora de Projetos de TI, possuindo experiência em gestão de sistemas sociais. Ministrou minicurso na ERSI-2018.

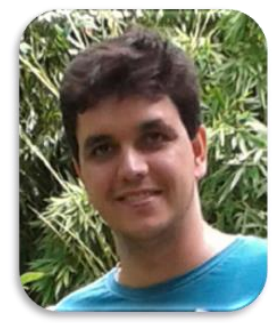

Marcelo Fornazin - http://lattes.cnpq.br/0396928965160154

Professor Adjunto no Instituto de Computação da Universidade Federal Fluminense e colaborador do PPGI da UNIRIO. Doutor em Administração pela EBAPE/FGV, possui Bacharelado e Mestrado em Ciência da Computação pela UNESP. Tem experiência na área de Computação, com ênfase em Gestão de TI, Governo Eletrônico e Computação Social. Atua nos seguintes temas: planejamento e gestão de TI, desenvolvimento de sistemas, desenvolvimento de soluções de informática na saúde e na educação.

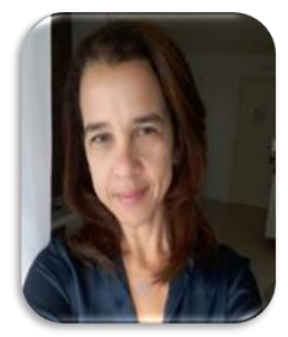

Renata Araujo - http://lattes.cnpq.br/3589012014320121

Professora permanente em tempo integral na Faculdade de Computação e Informática da Universidade Presbiteriana Mackenzie, São Paulo. Membro da Comissão Especial de Sistemas de Informação da SBC (2010 ao presente) e Diretora de Educação da SBC (20182019). Doutora em Engenharia de Sistemas e Computação pela COPPE/UFRJ. Coordenadora do Grupo de Pesquisa e Inovação em Ciberdemocracia (CIBERDEM). Pesquisadora do LUDES - Laboratório de Ludologia, Engenharia e Simulação da COPPE/UFRJ. Bolsista de Produtividade em Desenvolvimento Tecnológico e Extensão Inovadora do CNPq. Possui 20 anos de experiência em docência, pesquisa, desenvolvimento tecnológico e inovação na área de Computação, com ênfase em SI, atuando nos temas: governo e democracia digital, gestão da inovação, gestão de processos de negócio, engenharia de software e sistemas colaborativos.

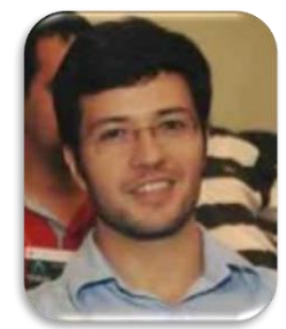

Rodrigo Pereira dos Santos-http://lattes.cnpq.br/8613736894676086 Professor Adjunto do Departamento de Informática Aplicada e membro efetivo do Programa de Pós-Graduação em Informática da Universidade Federal do Estado do Rio de Janeiro (UNIRIO). Doutor em Engenharia de Sistemas e Computação pela COPPE/UFRJ e pesquisador visitante na University College London (2014-2015). É editor-chefe da iSys: Revista Brasileira de Sistemas de Informação. É membro da Sociedade Brasileira de Computação desde 2006 e membro do Comitê Gestor da Comissão Especial de Sistemas de Informação (CESI) da SBC. Tem experiência na área de Ciência da Computação, com ênfase em Engenharia de Software 
e Sistemas de Informação. Seus principais campos de atuação são Ecossistemas de Software, Engenharia de Requisitos, Educação em Engenharia de Software e Aquisição de Software e Serviços de TI. Ministrou minicursos no SBSI, CLEI, SBIE, CBSoft, SBGames, SBQS, Webmedia, IHC, CIbSE e ICTAC, além de vários eventos regionais. 